\title{
Sondertagung 1990 in Berlin
}

Den Zusammenbruch der Diktatur hatte niemand vorhergesehen. Seit Monaten hatten zwar die Massenflucht aus der DDR und die Proteste innerhalb des Landes die Aufmerksamkeit der Weltöffentlichkeit auf sich gezogen. Als aber in der Nacht vom 9. auf den 10. November 1989 die SED-Regierung die Grenzübergänge zur Bundesrepublik einschließlich derer nach Westberlin öffnen ließ, kam dies für alle, selbst für die Protestierenden überraschend. Die Bilder der Freude und zugleich der Erschütterung der aus der Geiselhaft entlassenen, jetzt ihre neu gewonnene Freiheit auskostenden, zu Tausenden in den Westen strömenden Menschen werden unvergessen bleiben.

Niemand war auf den Wandel vorbereitet, auch nicht die deutsche Staatsrechtslehre. Durch Zufall hatte sich der auf der Tagung in Hannover neu gewählte Vorstand der Vereinigung zu seiner ersten Sitzung für den 11. November in Göttingen verabredet. Die Stadt hatte an diesem Tag ihr Gesicht verändert: sie war voll von DDRBesuchern, vollgeparkt von ihren kleinen Kraftfahrzeugen (den „Trabbis“). Den drei Vorstandsmitgliedern war klar: was sie miterlebten, war ein verfassungsrechtlicher Vorgang, so tiefgreifend, wie es ihn seit der Neugründung der Vereinigung im Jahre 1949 noch nicht gegeben hatte.

Zwar konnte niemand absehen, wie es weitergehen werde. Aber es war doch andererseits auch sicher, daß die Entwicklung auf dem Stand dieses 11. November nicht stehenbleiben konnte. Für die Vereinigung der Deutschen Staatsrechtslehrer bedeutete dies: der Vorstand mußte den Mitgliedern Gelegenheit geben, ihre wissenschaftlichen Auffassungen zur neuen verfassungsrechtlichen Lage nicht nur durch Aufsätze, sondern auf einer Tagung, in Rede und Gegenrede, auszutauschen. So beschloß der Vorstand, zu einer Sondertagung einzuladen, die für den 27. April in Berlin angesetzt wurde. Daß, wie immer die weitere Entwicklung verlaufen werde, jeder Tagungstermin im Hinblick auf bestimmte Ereignisse zu spät, im Hinblick auf andere zu früh kommen werde, war klar; daß der gewählte Termin sich am Ende als recht günstig erweisen werde, ließ sich nicht ahnen. 
Die Referate und die Diskussion der Tagung sind nachstehend wiedergegeben. Herr Bundespräsident Richard von Weizsäcker zeichnete die Referenten dadurch aus, $\mathrm{da} ß$ er an ihren Vorträgen teilnahm, und empfing die Tagungsteilnehmer nach Abschluß ihrer Beratungen in Schloß Bellevue. Herr Horst Sendler, Präsident des Bundesverwaltungsgerichts, stellte in großzügiger Weise für die Tagung den Plenarsaal seines Hauses zur Verfügung. Herr Günter Zebner, Vizepräsident des Bundesverwaltungsgerichts, begrüßte die Versammelten in seinem Namen. Die Aussprache leitete Herr Volkmar Götz. Nicht unerwähnt bleiben darf, daß die vier Kollegen, die der Vorstand um Referate gebeten hat, Jochen Abr. Frowein, Josef Isensee, Christian Tomuschat und Albrecht Randelzhofer, diese besonders schwierige Aufgabe angesichts der relativ kurzen Frist und der sich ständig verändernden politischen Lage - ohne Zögern übernommen haben. Ihnen allen gebührt besonderer Dank.

K. V. 